\title{
Nitric Oxide Regulates Mitochondrial Fatty Acids and Promotes CBF Expression of Peach Fruit during Cold Storage
}

\author{
Xiaoshan Guo ${ }^{1,2, \#}$, Dandan Huang ${ }^{2, \#}$, Siyu Wen ${ }^{2}$, Yang Bai ${ }^{2}$, Shuhua Zhu ${ }^{2, *}$ and Jianrong Feng ${ }^{1, *}$ \\ ${ }^{1}$ Department of Horticulture, College of Agriculture, Shihezi University, Shihezi, 832000, China \\ ${ }^{2}$ College of Chemistry and Material Science, Shandong Agricultural University, Taian, 271018, China \\ *Corresponding Authors: Shuhua Zhu. Email: shuhua@sdau.edu.cn; Jianrong Feng. Email: fengjr102@126.com \\ \#They contributed equally to this paper \\ Received: 23 June 2021 Accepted: 09 July 2021
}

\begin{abstract}
Low-temperature storage is convenient for postharvest preservation of peach fruit, but peach fruit is sensitive to cold damage, which lowers its quality. Nitric oxide (NO) has the potential to improve the bitter resistance of peach fruit. In this work, peach fruit was treated with $15 \mu \mathrm{mol} \mathrm{L}^{-1} \mathrm{NO}$ and $5 \mu \mathrm{mol} \mathrm{L}{ }^{-1}$ c-PTIO [2-(4-carboxyphenyl)-4,4,5,5-tetramethylimidazoline-1-oxo-3-oxide], to study changes in mitochondrial fatty acids and expression of the C-repeat binding factor $(C B F)$. The results showed that $15 \mu \mathrm{mol} \mathrm{L} \mathrm{L}^{-1}$ exogenous NO significantly maintained fruit quality, reduced peroxidation of mitochondrial fatty acids, increased the activities of the antioxidants superoxide dismutase (SOD), peroxidase (POD), catalase (CAT), ascorbic acid peroxidase (APX), and reduced the content of hydrogen peroxide $\left(\mathrm{H}_{2} \mathrm{O}_{2}\right)$. Meanwhile, $\mathrm{NO}$ treatment suppressed the increase in browning index and ion leakage rate, increased the activity of S-nitrosoglutathione reductase (GSNOR), the contents of S-nitrosothiols (SNOs), and the ratios of mitochondrial $\mathrm{NAD}^{+} / \mathrm{NADH}$ and $\mathrm{NADP}^{+} / \mathrm{NADPH}$, increased the expression levels of $P p C B F 1 / 5 / 6$. However, the expression levels of $P p C B F 2 / 3 / 4$ were not significantly regulated by exogenous NO. Peaches treated with c-PTIO showed opposite effects to those treated with exogenous NO. These results suggest that exogenous $\mathrm{NO}$ can improve antioxidant capacity, preserve mitochondrial fatty acids, and upregulate the expression of $P p C B F 1 / 5 / 6$ to alleviate cold tolerance and maintain the peach quality during storage.
\end{abstract}

\section{KEYWORDS}

Peach; cold storage; nitric oxide; mitochondrial fatty acid; $C B F$

\section{Introduction}

Peach fruits (Prunus persica) are delicious, nutritious and loved by consumers around the world, but they deteriorate quickly at room temperature. Cold storage is a beneficial way to extend the commercial life of peach fruit after harvest. However, peach fruits are exposed to low temperatures during continuous cold storage, and are prone to cold damage [1]. Cold damage is the most important factor affecting the quality and lifespan of peach fruits during cold storage, characterized by loss of taste and maturing capacity, rotting, pulp breakage, lack of fleshy quality, and ultimately pulp discoloration [2,3]. Both membrane fatty acids and $\mathrm{C}$-repeat binding factors $(C B F s)$ contribute to the reaction of plants to cold stress. 
The membrane is the major site that responds to frosty stress and damage, and plant membrane dysfunction is considered to be the most important factor in cold damage [4,5]. Fatty acids are the main components of the plasma membrane (PM) and play a significant role in the fat metabolism of such membrane [6]. The most common fatty acids in plants are palmitic acid (16:0), stearic acid (18:0), oleic acid (18:1), linoleic acid (18:2), and $\alpha$-linolenic acid (18:3). Low temperatures can change the composition of the membrane lipid of fruits [7]. Unsaturated fatty acids (UFAs) are the key factors for cold resistance. The unsaturated fatty acid index (IUFA) characterizes the cold resistance of plants [8]. The ingredient defines the architecture and robustness of the membrane lipids and reacts to cold damage to horticultural products [5].

Plant $C B F$ s are the first wave of genes that respond to cold acclimatization and tolerance [9]. Plant CBF proteins are familiarly coded by one gene family, and different genes of this family show different expressing methods in response to low-temperature stress [10,11]. The dependent metabolic pathway of $C B F$ is considered to be an important cold-resistant metabolic pathway in higher plants. As the hub of this signaling pathway, $C B F$ can receive signals from secondary messenger substances such as $\mathrm{NO}$ and $\mathrm{Ca}^{2+}$ and induce the expression of COR (cold reaction gene). This gene encodes a number of cold protection proteins to protect plant cells from cold damage [12]. The up-regulation of $C B F$ gene expression greatly increases the resistance of plants to cold stress $[12,13]$.

As a gaseous diatomic free radical, NO has been determined as a stress-resistant broad-spectrum agent and is the endogenous signal biomolecule that maintains the relationship between plant growth and plant developmental pathways [14,15]. NO reacts with GSH to form GSNO, the intracellular store of NO, and GSNOR converts GSNO into oxidized glutathione (GSSG) and ammonium ions [16]. Exogenous NO increases the activities of antioxidant enzymes and reduces the accumulation of ROS, protects the integrity of the cell membrane, and protects the fruit from CI after harvest [17,18]. NO also regulates the fatty acid composition and the sphingolipid metabolism of peach fruits after harvest $[4,19]$, modifies the unsaturated fatty acids to be nitrated fatty acids in reaction to abiotic stress in plants [20], interactives with the ingredient of the plant mitochondria, electron transport chain and is involved in mitochondrial functions [21,22]. The expression of $C B F$ in fruits was upregulated to varying degrees under cold storage [18].

Mitochondrial fatty acids are the source of energy, constitute the mitochondrial membrane, are involved in the processes of protein modification [23], and $C B F$-dependent transcription regulation improves the cold tolerance of plants [24]. The CBF genes of peach fruits are expressed differently during cold storage and the preservation period [10]. However, very little is known about the changes in mitochondrial fatty acids and the expression of $C B F$ in peaches under NO treatment during cold storage. In this paper, peach fruit was treated with exogenous NO and c-PTIO as a NO scavenger. The purposes of this study were to primarily study the regulation by $\mathrm{NO}$ on the changes in mitochondrial fatty acids and the expression of $C B F$ of peaches under cold stress during storage.

\section{Materials and Methods}

\subsection{Fruits and Treatment Methods}

Peaches used in the study were obtained from a commercial orchard in Taian, Shandong Province, with an average hardness of about $80 \mathrm{~N} \mathrm{~cm}^{-2}$ and soluble sugar content of about $7.5^{\circ} \mathrm{Brix}$, and similar size and color, free from defects and mechanical damage. The peach was precooled to $0^{\circ} \mathrm{C}$ for $24 \mathrm{~h}$ and then soaked for $15 \mathrm{~min}$ in $15 \mu \mathrm{mol} \mathrm{L}{ }^{-1} \mathrm{NO}$ solution with distilled water as a control and c-PTIO solution $\left(5 \mu \mathrm{mol} \mathrm{L} \mathrm{L}^{-1}\right)$ as NO scavenger. The NO concentration of $15 \mu \mathrm{mol} \mathrm{L}{ }^{-1}$ was selected founded on the results of preliminary work [22,25], according to Lim et al. [26]. The concentration was measured with a NO probe (ISONOPF200, World Precision Instruments, Sarasota, FL, USA), after soaking and subsequent removal of the fruit, and air-drying at $0^{\circ} \mathrm{C}$ for storage. 


\subsection{Determination of Browning Index, Ion Leakage, and $\mathrm{H}_{2} \mathrm{O}_{2}$ Fruit Content}

The browning index of the fruit kernel was rated five ranks according to the degree of browning [27]. The browning index was calculated according to the following formula: browning index $=\sum$ (fruit fraction $\times$ fruit count $) /(5 \times$ total fruit count $) \times 100 \%$.

The ion leakage was measured with a DDS-307 conductivity meter (Leici, Shanghai, China). The peach fruit was sliced approximately $1 \mathrm{~mm}$ thin, immersed in distilled water, and the conductivity was recorded initially (P0), after $10 \mathrm{~min}$ of incubation (P1), and after boiling and cooling at room temperature (P2). The ion leakage was computed by the following formula: ion leakage $=(\mathrm{P} 1-\mathrm{P} 0) /(\mathrm{P} 2-\mathrm{P} 0) \times 100 \%$.

The endogenous $\mathrm{H}_{2} \mathrm{O}_{2}$ content was identified using the method of Patterson et al. [28]. The absorbance at $415 \mathrm{~nm}$ was determined using a standard curve of known $\mathrm{H}_{2} \mathrm{O}_{2}$ concentrations on a fresh weight (FW) basis, expressed as $\mu \mathrm{mol} \mathrm{g}^{-1}$.

\subsection{Determination of SOD, POD, CAT, and APX Enzyme Activities on Fruit Mitochondria}

SOD activity was monitored by assessing the inhibition of nitro-blue-tetrazolium (NBT) reduction by light using the method of Liu et al. [29]. The mitochondrial suspension was added to $3 \mathrm{~mL}$ of the reaction solution (containing methionine, nitrogen blue tolazoline, EDTA, riboflavin), and the fluorescence was irradiated at 400lux. The photoreduction rate of $50 \%$ NBT inhibition per unit time was used as a unit of enzyme activity $\mathrm{U}$. SOD activity was expressed as $\mathrm{U} \mathrm{g}^{-1}$ protein.

POD activity was given in reference to the method of Wang et al. [30]. The absorbance changes of mitochondrial suspension and phosphate buffer (containing guaiacol and 30\% hydrogen peroxide) were measured at $470 \mathrm{~nm}$. POD activity of mitochondria within the mitochondria was defined as a change in absorbance per unit time of 0.01 one unit of enzyme activity U. POD activity was expressed as $\mathrm{U} \mathrm{g}^{-1}$ protein. $^{2}$

CAT activity was determined by the reference method of Baniebrahim et al. [31]. The absorbance change of mitochondrial suspension containing $50 \mathrm{mmol} \mathrm{L}^{-1}$ phosphate buffers and $0.3 \%(\mathrm{v} / \mathrm{v}) \mathrm{H}_{2} \mathrm{O}_{2}$ solution was detected at $240 \mathrm{~nm}$. The change in absorbance per unit of time was 0.01 as a unit of enzyme activity. CAT activity was expressed as $\mathrm{Ug}^{-1}$ protein.

APX activity in strawberries was determined according to the method of Ghosh et al. [32]. $200 \mu 1$ of mitochondrial suspension family sodium phosphate buffers (containing EDTA, ASA, and hydrogen peroxide) were used to assess the change in absorbance at $290 \mathrm{~nm}$. The change in absorbance per unit of time is 0.01 as a unit of enzyme activity. APX activity was expressed as $\mathrm{U} \mathrm{g}^{-1}$ protein.

\subsection{Determination of the Contents of Mitochondrial NAD, NADH, NADP, and NADPH}

The mitochondria were isolated and purified using the methodology of $\mathrm{Xu}$ et al. [33]. The protein content of the mitochondrial suspension was quantified using the method of Coomassie brilliant blue [34]. The contents of mitochondrial NAD and NADH were determined by the $\mathrm{NAD}^{+} / \mathrm{NADH}$ quantitative kit (MAK037, Sigma-Aldrich, USA). The ratio of NAD/NADH was calculated according to the following formula: $\mathrm{NAD} / \mathrm{NADH}=\left(\mathrm{NAD}_{\text {total }}-\mathrm{NADH}\right) / \mathrm{NADH}$. The contents of mitochondrial $\mathrm{NADP}^{+}$ and NADPH were determined by the NAPD ${ }^{+}$NADPH quantitative kit (MAK038, Sigma-Aldrich, USA) and expressed by mmol $\mathrm{g}^{-1}$ protein. The ratio of $\mathrm{NADP}^{+} / \mathrm{NADPH}$ was calculated by the following formula: $\mathrm{NADP} / \mathrm{NADPH}$ ratio $=\left(\mathrm{NADP}_{\text {total }}-\mathrm{NADPH}\right) / \mathrm{NADPH}$.

\subsection{Determination of Mitochondrial S-Nitrosoglutathione Reductase (GSNOR) Activity}

GSNOR activity was calculated by monitoring the degradation of NADH [35]. At $340 \mathrm{~nm}$, the absorbance change of the mitochondrial suspension was measured after GSNO was added to the final concentration of $0.4 \mathrm{mmol} \mathrm{L}^{-1}$. GSNOR activity was indicated as mmol NADH $\mathrm{min}^{-1} \mathrm{~g}^{-1}$ protein. 


\subsection{Determination of Mitochondrial S-Nitrosothiols (SNOs) Content}

The content of SNOs was determined according to Frungillo et al. [36]. Mitochondrial solutions (100 $\mu \mathrm{L})$ were mixed with $100 \mu \mathrm{L}$ solutions $\mathrm{A}$ [containing sulfanilamide and N-(1-Naphthyl) ethylene-diamino dehydrogenate] and $100 \mu \mathrm{L}$ solution $\mathrm{B}$ (containing solution A and $\mathrm{HgCl}_{2}$ ), respectively. The absorbance at $540 \mathrm{~nm}$ was minuted after reaction under dark for $10 \mathrm{~min}$. Content of SNOs was quantified according to the difference between the measured values of solution A and B and calculated with the standard curve of GSNO.

\subsection{Analysis of Fatty Acids}

Fatty acids were analyzed by gas chromatography/mass spectrometry (GC/MS) [37]. Purified mitochondria was re-suspended with $1 \mathrm{~mL}$ of $\mathrm{CHCl}_{3} /$ methanol/formic acid $(1: 1: 0.1, \mathrm{v} / \mathrm{v} / \mathrm{v})$. Then $0.5 \mathrm{~mL}$ of $\mathrm{KCl} / \mathrm{H}_{3} \mathrm{PO}_{4}$ was added to the solution. After shaking vigorously, the mixture was centrifuged at $9000 \times \mathrm{g}$ for $3 \mathrm{~min}$ to be stratified into two layers. The lower organic phase was transferred into a clean centrifuge tube, and then $0.5 \mathrm{~mL}$ of $\mathrm{CHCl}_{3} /$ methanol $(2: 1, \mathrm{v} / \mathrm{v})$ was added into it. After blending, the mixture was evaporated in a rotary vacuum evaporator. The residue was then resolved by $100 \mu \mathrm{L}$ of $\mathrm{CHCl}_{3} /$ methanol $(2: 1, \mathrm{v} / \mathrm{v})$. Then, $0.4 \mathrm{~mL}$ of $0.4 \mathrm{~mol} \mathrm{~L}^{-1} \mathrm{KOH}-m e t h a n o l$ and $0.4 \mathrm{~mL}$ of benzenepetroleum ether $(1: 1, \mathrm{v} / \mathrm{v})$ were added into the solution. After vigorous shake, the mixture was incubated for $20 \mathrm{~min}$ and mixed with $3 \mathrm{~mL}$ of distilled water. The mixture was then shaken, and the higher phase was transferred into a new tube and centrifuged for $10 \mathrm{~min}$ at $12,000 \times \mathrm{g}$. The supernatant was the methyl ester of membrane lipids. Mitochondrial fatty acids of peaches were assayed by a 450GC-300MC GCMS (Varian, USA) with a FID detector. The chromatographic conditions were: BR-5 ms column (30 $\mathrm{m} \times$ $0.25 \mu \mathrm{m} \times 0.25 \mu \mathrm{m}$ ), the injection temperature of FID detector was $250^{\circ} \mathrm{C}$, and the injection volume was $1.0 \mu \mathrm{L}$, the split ratio was 50:1. The temperature program was as follows: the initial oven temperature of $150^{\circ} \mathrm{C}$ was held for $1 \mathrm{~min}$, then programmed to increase with $10^{\circ} \mathrm{C} \mathrm{min}{ }^{-1}$ to $200^{\circ} \mathrm{C}$ and hold for $8 \mathrm{~min}$, the temperature was increased with $8^{\circ} \mathrm{C} \mathrm{min}{ }^{-1}$ to $250^{\circ} \mathrm{C}$ and hold for $5 \mathrm{~min}$. Helium was used as carrier

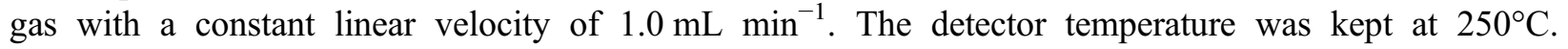
Characterization and identification of fatty acid methyl esters (FAMEs) were performed in the scan mode. The mass spectrometry conditions were: electronic ignition (EI) source, the temperature of it was $230^{\circ} \mathrm{C}$, the electron energy was $70 \mathrm{eV}$, and the electron multiplier voltages were $1500 \mathrm{~V}$. The interface temperature was $250^{\circ} \mathrm{C}$, the solvent delay time was $2.5 \mathrm{~min}$ and the mass scan range was $\mathrm{m} / \mathrm{z} 40-550$. Components were identified by comparisons of retention times and peak curves with authentic standards. The analysis of the detection result was based on the combination of the results of research through a mass spectrometry database and artificial spectra analysis. The proportion of each fatty acid was expressed as mol\% of the total fatty acids. IUFA (index of unsaturated fatty acid) was calculated by the following formula: IUFA $=[18: 1 \%+(18: 2 \%) \times 2+(18: 3 \%) \times 3] \times 100 \%$, where 18:1 $=$ oleic acid, 18:2= lineage acid, and 18:3 $=\alpha$-linolenic acid.

\subsection{Determination of MDA Content and LOX Activity}

Determination of malondialdehyde (MDA) was carried out according to the methodology of Senthilkumar et al. [38]. The absorbance of a mixture of mitochondria, trichloroacetic acid, and phenobarbital acid (TBA), measured at 532 and $600 \mathrm{~nm}$, was recorded. It was calculated using the standard curve and the absorption coefficient at $1.53 \mathrm{mmol} \mathrm{L}^{-1}$, expressed as mmol g $\mathrm{g}^{-1}$ protein.

Determination of mitochondrial LOX activity was carried out according to the methodology of Palma et al. [39]. The protein content of the mitochondrial suspension was quantified using the procedure of Coomassie Brilliant Blue [34]. LOX activity was reported in $\mathrm{U} \mathrm{min}^{-1} \mathrm{~g}^{-1}$ protein. 


\subsection{Determination of Calcium Content}

Mitochondrial $\mathrm{Ca}^{2+}$ content was determined with the specific fluorescent probe $\mathrm{Rhod}^{-2}$, according to the instructions of the fluorescence Quantitative Detection Kit for calcium concentration in Mitochondria (Mingxiu, Shanghai, China). The relative fluorescence units (RFU) of the sample holes $\left(\mathrm{RFU}_{\text {sample }}\right)$, the blank control hole without mitochondria $\left(\mathrm{RFU}_{\text {blank }}\right)$, the largest control hole without mitochondria ( $\mathrm{RFU}_{\text {largest }}$ ), were detected with a SuPerMax 3000FA fluorescence microplate reader (Shanghai, China). Mitochondrial $\mathrm{Ca}^{2+}$ content was expressed as $\mu \mathrm{mol} \mathrm{\textrm {g } ^ { - 1 }}$ protein.

Mitochondrial $\mathrm{Ca}^{2+}$ content $=\frac{R F U_{\text {sample }}-R F U_{\text {blank }}}{R F U_{\text {largest }}-R F U_{\text {sample }}} \times \frac{570}{\text { protein content }}$

\subsection{Analysis of Expression Level of PpCBFs}

The total RNA was extracted from peaches following the method of Meisel et al. [40] and resuspended in water treated with diethylpyrocarbonate (DEPC). The purity and concentration of RNA were evaluated by a Q5000 microvolume spectrophotometer (Quawell, USA). The RNA was reversed transcribed into cDNA by a PrimeScript ${ }^{\mathrm{TM}}$ II1st Strand cDNA Synthesis Kit (Takara, Dalian China). Six members of the CBF gene family were obtained from the NCBI database (https:/www.ncbi.nlm.nih.gov/) with the gene ID as $18776669,18776400,18787317,18777414,18776409,18778067$, respectively, and denoted as $P p C B F 1$ PpCBF6. Changes in expression of PpCBF1-PpCBF6 were analyzed with a CFX 96 Real-Time PCR Detection System (Bio-Rad, Berkeley, USA) according to the method of Guan et al. [41]. TEF2 (TC3544) of peach was used as the reference gene, and the specific primers of TEF2 were designed (Tab. 1).

Table 1: The sequences of the specific primers

\begin{tabular}{|c|c|}
\hline Primer name & Primer sequence \\
\hline \multirow[t]{2}{*}{$P p C B F 1$} & F: 5'-CACGAGCAGCCATCTCAGCC-3' \\
\hline & R: 5'-GTTTTCAAGGAGACGAGGCAC-3' \\
\hline \multirow[t]{2}{*}{$P p C B F 2$} & F: 5'-GTGGTGAATGAGGAGAAGGGT-3' \\
\hline & R: 5'-GCCATCTAAGCACTGAGGTGGACAA-3' \\
\hline \multirow[t]{2}{*}{$P p C B F 3$} & F: 5'-AGCCCAACAAGAAGACCAGGAT-3' \\
\hline & R: 5'-GGAGTCGGCAAAGTTCAAGCA-3' \\
\hline \multirow[t]{2}{*}{$\mathrm{PpCBF4}$} & F: 5'-GCTTGCCTGCCTCAACTTCC-3' \\
\hline & R: 5'-GGACACTCCACCAAACTCCACC-3' \\
\hline \multirow[t]{2}{*}{$P p C B F 5$} & F: 5'-TTTCAAGGAGACGAGGCACC-3' \\
\hline & R: 5'-GGCACGAGCAGCCATCT-3' \\
\hline \multirow[t]{2}{*}{ PpCBF6 } & F: 5'-GCTTGCCTGCCTCAACTTTGC-3' \\
\hline & R: 5'-ACTGCTGCCGCTGGAAACCC-3' \\
\hline \multirow[t]{2}{*}{ TEF2 } & F: 5'-GGTGTGACGATGAAGAGTGATG-3' \\
\hline & R: 5'-TGAAGGAGAGGGAAGGTGAAAG-3' \\
\hline
\end{tabular}

\subsection{Data Analysis}

All experiments were performed using three biological replicates. The data were analyzed according to the method of two-way ANOVA with treatment (T) and storage time (S) as factors (LSD, $P<0.05)$. Error bars indicate the standard errors of the means of three replicates. 


\section{Results}

\subsection{Peach Fruit from Different Treatments after Four Weeks of Storage}

The appearance of peach fruits from the different treatments after four weeks of storage is shown in Fig. 1. Slight localized decay occurred in the control-treated fruit, while severe decay and even mould occurred in the c-PTIO-treated fruit. Compared to the control and c-PTIO treatments, exogenous NOtreated fruit maintained a good morphological appearance of the peach fruit throughout storage.

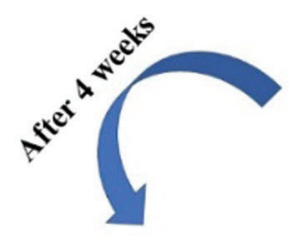

Control

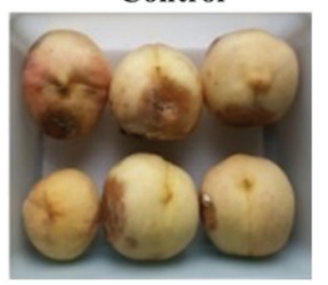

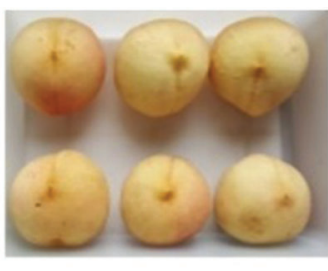

c-PTIO

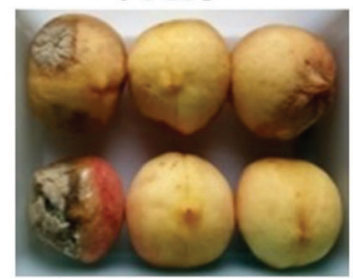

0 day

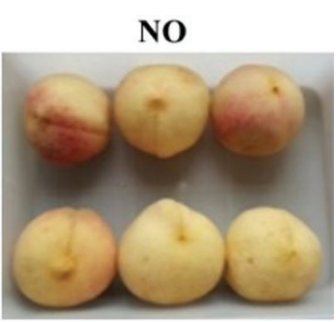

Figure 1: Appearance of the peaches in different treatments after 4 weeks of storage

\subsection{Determination of Fruit Storage Quality}

The browning index of peach increases continuously during cold storage (Fig. 2A). The increasing trend of the browning index of the exogenous NO treatment was slower than that of the other treatments. The browning index of peach fruits exogenous NO treated increased slowly in the first 3 weeks, and more rapidly after 3 weeks. The browning index of the fruits treated with NO treated was $34.4 \%$ in the 4 th week, which corresponded to $61.1 \%$ of the control value. However, the browning index of the peach fruit treated with c-PTIO was higher than the control after week 3. Exogenous NO treated had an apparent inhibitory effect on peach tan.

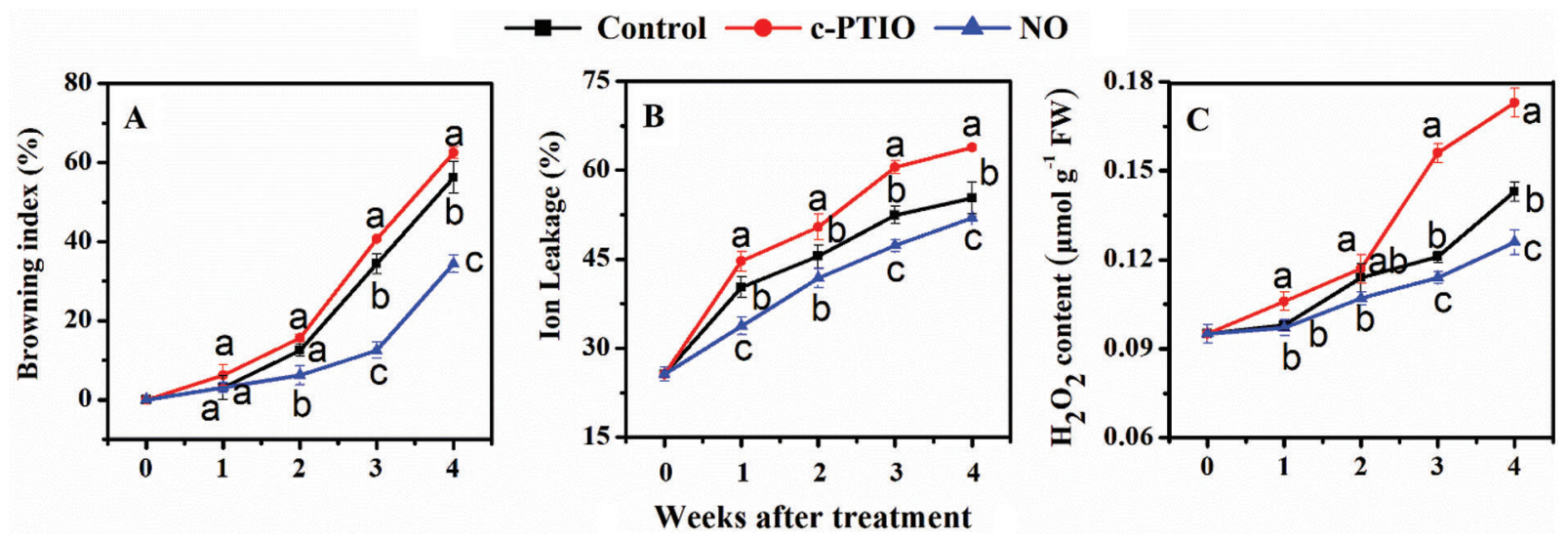

Figure 2: Changes in the browning index (A), ion leakage (B), and $\mathrm{H}_{2} \mathrm{O}_{2}$ content (C) of peaches 
The ion permeation of peach fruits showed an upward trend during cold storage (Fig. 2B). The ion leak rate of peach exogenous NO-treated was much lower than that of other treatments. The ion leakage rate from c-PTIO-treated fruits was much higher than that of the control. The results showed that the increase in ion permeation in peach fruits was significantly inhibited in the by exogenous NO treated.

The $\mathrm{H}_{2} \mathrm{O}_{2}$ content of peaches was gradually promoted during cold storage (Fig. 2C). The $\mathrm{H}_{2} \mathrm{O}_{2}$ content of peach fruits exogenous NO treated was much lower than that of the controls after the 3rd week. After the 3rd week, however, the $\mathrm{H}_{2} \mathrm{O}_{2}$ content of c-PTIO-treated was higher than that of the control.

\subsection{Changes in the Activity of LOX and the Contents of Mitochondrial MDA and Ca ${ }^{2+}$}

During storage, peach mitochondrial LOX activity decreased dramatically (Fig. 3A). In the first 3 weeks, mitochondrial LOX activity of NO treated was much lower than that of the control. In the 1st week, in particular, LOX activity of NO treated was only $48.5 \%$ of the control. Mitochondrial LOX activities of c-PTIO treated increased dramatically after week 2 during cold storage.
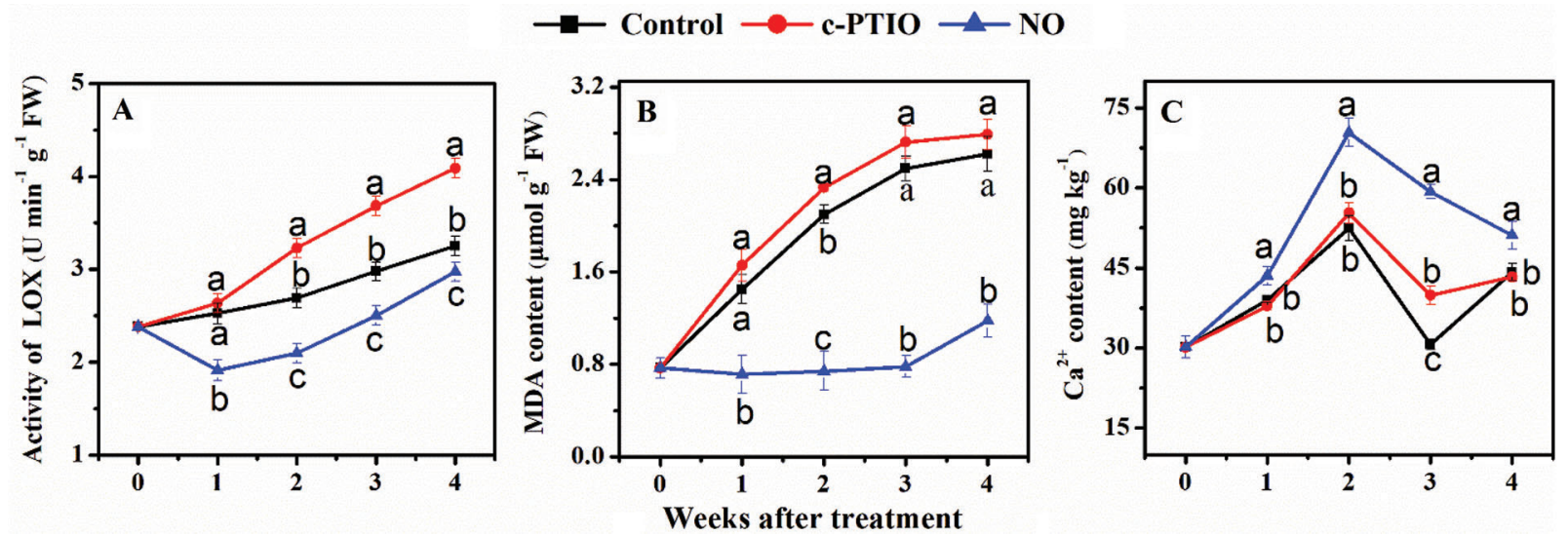

Figure 3: Changes in the activity of mitochondrial LOX (A), the mitochondrial contents of MDA (B) and $\mathrm{Ca}^{2+}$ of peaches (C) during storage

The mitochondrial MDA content in peaches increased during cold storage (Fig. 3B). There were no significant differences in mitochondrial MDA levels between the other treatments. Mitochondrial MDA content of NO-treated changed gently and was much lower than that of the control during storage.

There was no much disparity in the mitochondrial $\mathrm{Ca}^{2+}$ content of peaches between c-PTIO treated and the control during storage, except in the 3rd week (Fig. 3C). Exogenous NO treated significantly increased the mitochondrial $\mathrm{Ca}^{2+}$ content in comparison of the control. The content of $\mathrm{Ca}^{2+}$ in NO treated was about 1.5 times as high as that of the control in the 3 rd week.

\subsection{Changes in Activities of Peach Fruit Mitochondrial SOD, POD, CAT, and APX Enzymes}

The SOD activity of peach fruits mitochondrial increased during refrigeration and decreased with increasing storage time (Fig. 4A). During the entire storage period, the highest activity was observed in NO-treated peach fruits, which reached their highest value in the second week. The SOD activity in the control and c-PTIO treated decreased rapidly after week 2 . At week 2, the SOD activity of NO treated peach fruits was significantly different from the other two treatments, and was 1.13 times higher than the control and 1.18 times higher than the c-PTIO treated. At week 4, the control treatment decreased by $32.16 \%$ compared to the NO treatment, and the c-PTIO treatment decreased by $22.38 \%$ compared to the NO treated. 

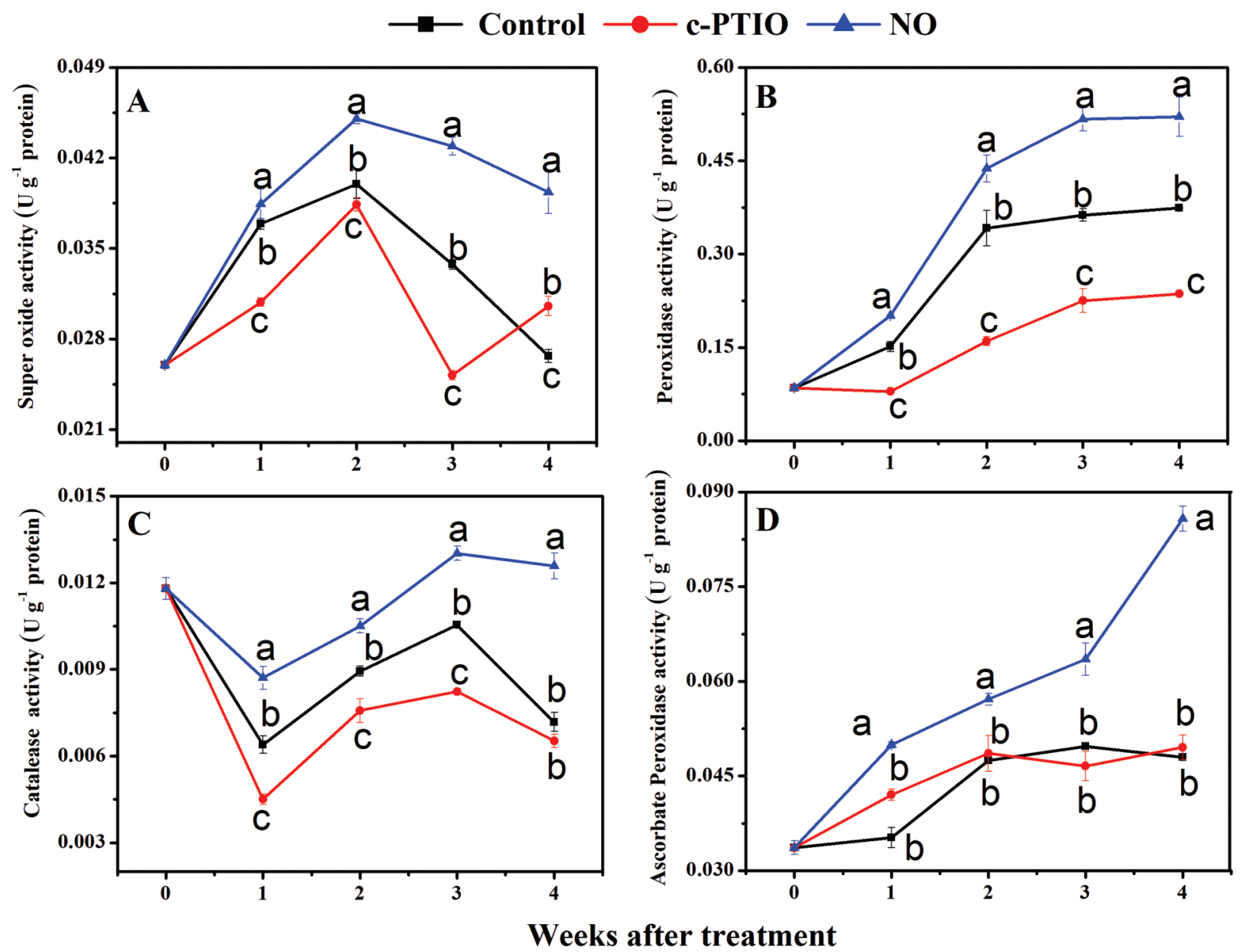

Figure 4: Changes in the activity of SOD (A), POD (B), CAT (C), and APX (D) during storage

During storage, the POD activity of peach fruits mitochondrial showed a tendency to increase first (Fig. 4B). The highest level of POD activity was maintained with NO treated throughout the cold storage period. POD activity of the NO treated peaked at the fourth week, and the POD activity of the NOtreated was $0.52 \mathrm{U} \mathrm{g}^{-1}$ protein, 1.39 times higher than the control treatment and 2.20 times higher than the c-PTIO treatment.

The trend in CAT enzyme activity in peach fruits mitochondrial after one week of refrigeration was decreased, followed by an increase (Fig. 4C). In the 3rd week, there was a 1.224-fold increase in NO treatment compared to the control and a 1.58-fold increase compared to the c-PTIO treatment. The NOtreated mitochondrial resulted in a much higher CAT activity than the other two treatments during the entire cooling process, which significantly increased the CAT enzyme activity, reduced the amount of hydrogen peroxide, and delayed fruit aging in the cold store.

APX activity in peach fruits mitochondrial from the various treatments tended to increase over time, with NO treatment being at a higher level (Fig. 4D). During the entire storage course, the APX activity of the NO-treated was higher than that of the other two treatments, with 0.08576 in the NO treatment at week four, 1.79 times higher than that of the control, and 1.73 times higher than that of the c-PTIO treatment. The differences between the NO treated and other treatments were significant. 


\subsection{Changes in Mitochondrial SNOs Content, GSNOR Activity, and the Ratios of NAD ${ }^{+} / \mathrm{NADH}$ and $N A D P^{+} / N A D P H$}

The content of mitochondrial SNOs was increased with a transient decrease in the 3rd week (Fig. 5A). Exogenous NO-treated significantly increased the level of mitochondrial SNOs, which was significantly greater than the control during storage. At week 4, mitochondrial SNO content of NO treated peaches was 1.36 times that of the control. c-PTIO-treated reduced the level of mitochondrial SNOs from the 1st to the 3rd week. Mitochondrial SNO content of c-PTIO treated was only $83.9 \%, 78.3 \%$, and $76.6 \%$ of the control in the 1st, 2nd, and 3rd week, respectively.
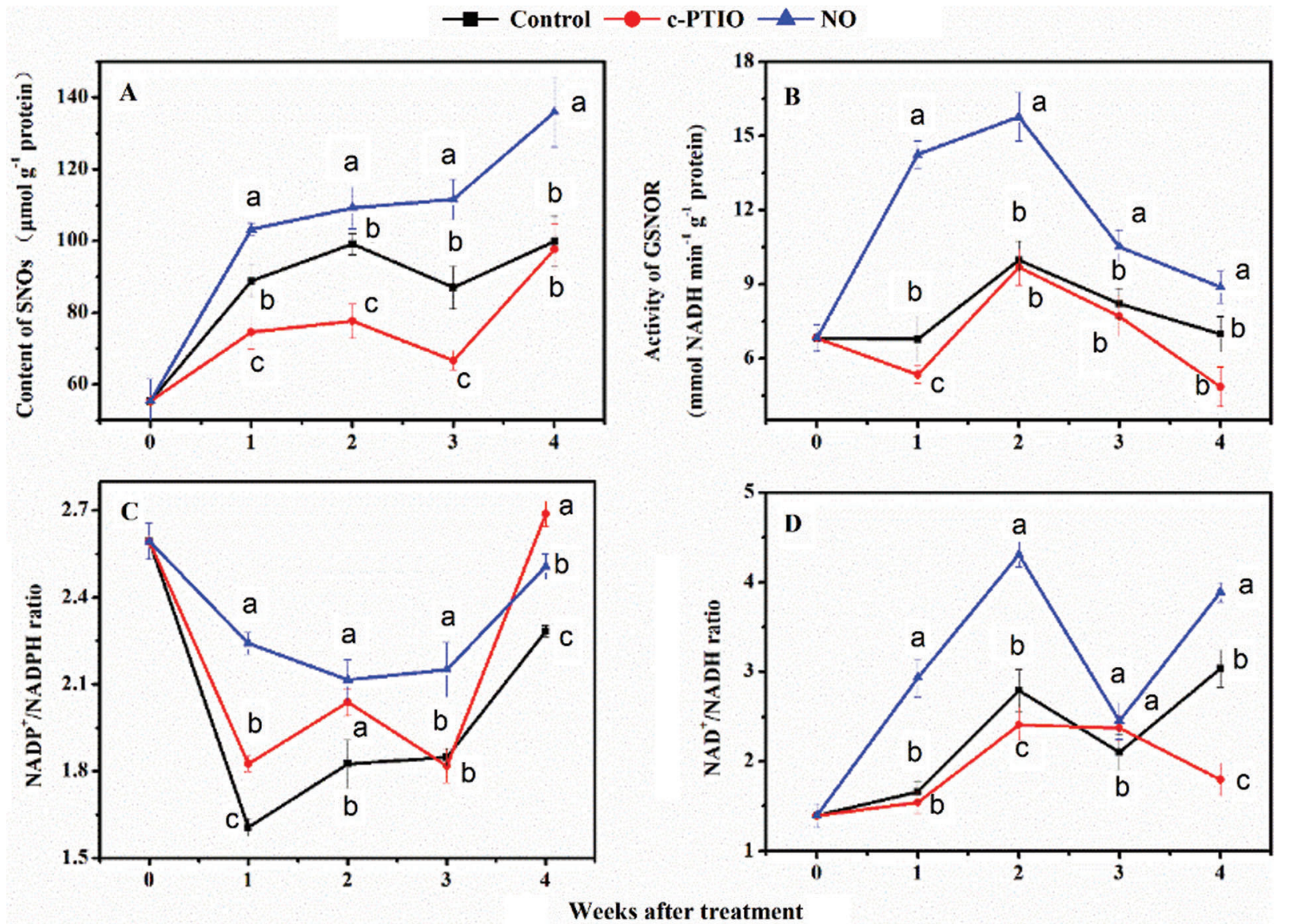

Figure 5: Changes in mitochondrial SNOs content (A), GSNOR activity (B), and the ratios of $\mathrm{NAD}^{+}$/ $\mathrm{NADH}(\mathrm{C})$ and $\mathrm{NADP}^{+} / \mathrm{NADPH}(\mathrm{D})$

Mitochondrial GSNOR activity in mitochondrial increased to a peak in week 2 and then decreased (Fig. 5B). Exogenous NO treated dramatically improved mitochondrial GSNOR activity. In particular, in weeks 1 and 2, the activity of mitochondrial GSNOR in mitochondrial of exogenous NO treated was 2.1 and 1.6 times that of the control, respectively. However, mitochondrial GSNOR activity of c-PTIO treated was only $78.8 \%$ and $69.5 \%$ of the control in the 1 st and 4 th week, respectively.

The mitochondrial $\mathrm{NAD}^{+} / \mathrm{NADH}$ ratio of NO-treated was much higher than that of the control during storage (Fig. $5 \mathrm{C}$ ). The mitochondrial $\mathrm{NAD}^{+} / \mathrm{NADH}$ ratio of NO-treated was $1.76,1.54,1.28$ times that of the control in 1st, 2nd, and 4 th week, respectively. The mitochondrial NAD ${ }^{+} / \mathrm{NADH}$ ratio of c-PTIO treated was $92.7 \%$ and $59.1 \%$ of the control in the 2 nd and 4 th week. 
Compared to the control, NO maintained a higher mitochondrial $\mathrm{NADP}^{+} / \mathrm{NADPH}$ ratio of peach during storage (Fig. 5D). The mitochondrial $\mathrm{NADP}^{+} / \mathrm{NADPH}$ ratio of exogenous $\mathrm{NO}$ treated was 1.23 and 1.18 times that of controls at weeks 1 and 3, respectively. However, c-PTIO treated reduced the $\mathrm{NADP}^{+} / \mathrm{NADPH}$ ratio during storage except in the 3 rd week. The mitochondrial $\mathrm{NADP}^{+} / \mathrm{NADPH}$ ratio of c-PTIO treated was only $87.9 \%, 89.5 \%$, and $91.5 \%$ of the control in the 1 st, 2 nd, and 4 th week.

\subsection{Mitochondrial Fatty Acids}

The total contents of mitochondrial fatty acids decreased in peaches during storage (Fig. 6A). Interestingly, both exogenous NO and c-PTIO treated delayed the decrease in mitochondrial fatty acids contents. The contents of mitochondrial fatty acids in peaches treated with NO treated was 1.47, 1.19, 1.66, 1.73 times of the control in the 1st, 2nd, 3rd, 4th week, respectively. The contents of mitochondrial fatty acids in c-PTIO treated were 1.14, 1.14, 1.26, 1.21 times of the control in the 1st, 2nd, 3rd, 4th week, respectively. However, the contents of mitochondrial fatty acids in NO-treated were higher than those of c-PTIO-treated.

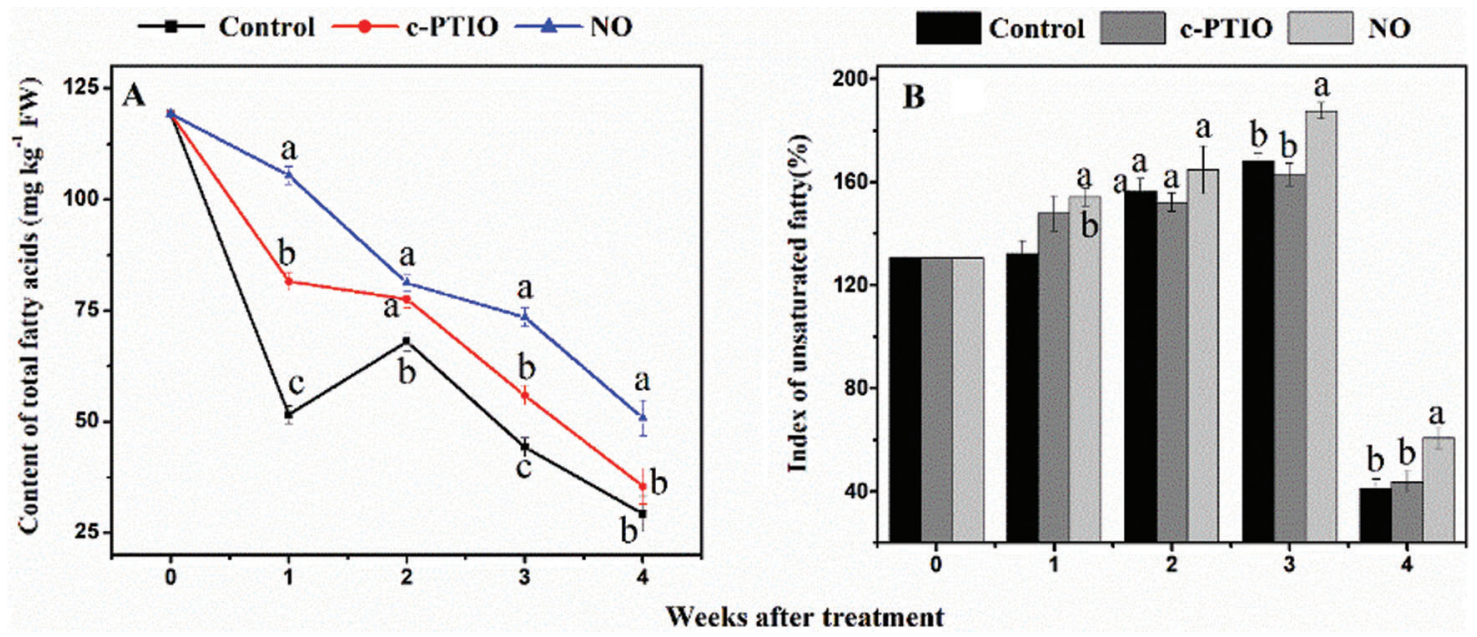

Figure 6: Changes in the content of total fatty acids (A) and the index of unsaturated fatty acids (B) in mitochondria of peaches during storage

Mitochondrial IUFA of peaches increased during the first 3 weeks and then decreased (Fig. 6B). NO treatment increased the mitochondrial IUFA considerably during storage. Mitochondrial IUFA of peaches treated with NO treated was 1.17, 1.12, 1.48 times the control in the 1st, 3rd, and the 4th week, respectively. On the 1 st week, mitochondrial IUFA of c-PTIO-treated was 1.12 times of the control; henceforth, no much discrepancy was found in mitochondrial IUFA between other treatments.

Palmitic acid (9.368 min), linoleic acid (13.767 min), $\alpha$-linolenic acid (13.934 min), oleic acid (14.120 $\mathrm{min}$ ), stearic acid (14.752 $\mathrm{min}$ ), and peanut acid (19.072 $\mathrm{min}$ ) were quantified in the mitochondria of peach fruit.

At week 0, palmitic acid, linoleic acid, and $\alpha$-linolenic acid accounted for $32.19 \%, 44.75 \%$, and $12.60 \%$ of total fatty acids, respectively, indicating that these three fatty acids were the major fatty acids in the mitochondria of peaches (Tab. 2). The other four fatty acids made up only $10.46 \%$ of the total fatty acids, of which arachidonic acid made up only $0.81 \%$. The proportion of these fatty acids in the mitochondria changed during storage. The palmitic acid content in the mitochondria of peach fruits shows a downward trend in the early stages of storage, and then rised in the later stage. The palmitic acid content of the 
mitochondria in NO treated decreased slightly in the first 3 weeks and increased sharply in the 4th week. In the 4th week, in particular, the palmitic acid content in NO treated was $62.24 \%$, which was significantly higher than that on the other treatments. During cold storage, the level of palmitic acid in the mitochondria of c-PTIO treated increased. The linoleic acid content of the control peach decreased for the first 2 weeks and then increased. During cold storage, the mitochondrial linoleic acid content of c-PTIO treated was only $7.12 \%$ of the total fatty acids in the 3rd week and increased to $15.8 \%$ in the 4th week. The linoleic acid content of NO treated peach decreased from $44.75 \%$ in week $0 \%$ to $11.39 \%$ in week 3 and then increased to $13.31 \%$ in week 4 , which was much lower than that of the control. During cold storage, the mitochondrial $\alpha$-linolenic acid content of peaches increased and then decreased for the first 2 weeks. The mitochondrial $\alpha$-linolenic acid content of NO treated increased from $12.60 \%$ in week $0 \%$ to $38.85 \%$ in week $2 \%, 46.79 \%$ in week 3 , and decreased sharply to $3.86 \%$ in week 4 . The mitochondrial $\alpha$ linolenic acid content of peaches treated with NO treated was higher than that of the c-PTIO treated except in the 3rd week, and higher than that of the control during storage in addition to the 2 nd week. The mitochondrial oleic acid content of c-PTIO treated was lower than that of the control in the 2nd and 3rd week. Mitochondrial oleic acid of NO treated decreased in the first 3 weeks, reaching the lowest level in the 3rd week, and increased in the 4th week.

Table 2: Contents of the mitochondrial fatty acids of Feicheng peaches with different treatments during cold storage (percent of the total fatty acids)

\begin{tabular}{llllllll}
\hline Week & Treatment & $\begin{array}{l}\text { Palmitic acid } \\
(\mathrm{C} 16: 0)\end{array}$ & $\begin{array}{l}\text { Linoleic acid } \\
(\mathrm{C} 18: 2)\end{array}$ & $\begin{array}{l}\alpha \text {-linolenic acid } \\
(\mathrm{C} 18: 3)\end{array}$ & $\begin{array}{l}\text { Oleic acid } \\
(\mathrm{C} 18: 1)\end{array}$ & $\begin{array}{l}\text { Stearic acid } \\
(\mathrm{C} 18: 0)\end{array}$ & $\begin{array}{l}\text { Arachidic acid } \\
(\mathrm{C} 20: 0)\end{array}$ \\
\hline 0 & & $32.19 \pm 1.12$ & $44.75 \pm 2.15$ & $12.60 \pm 0.27$ & $2.70 \pm 0.06$ & $3.76 \pm 0.07$ & $0.81 \pm 0.02$ \\
1 & Control & $30.67 \pm 0.33 \mathrm{a}$ & $34.56 \pm 0.45 \mathrm{a}$ & $19.92 \pm 0.36 \mathrm{c}$ & $2.85 \pm 0.09 \mathrm{~b}$ & $4.57 \pm 0.11 \mathrm{a}$ & $1.58 \pm 0.02 \mathrm{a}$ \\
& NO & $30.71 \pm 2.54 \mathrm{a}$ & $23.39 \pm 0.07 \mathrm{c}$ & $34.80 \pm 1.21 \mathrm{a}$ & $2.35 \pm 0.12 \mathrm{c}$ & $4.46 \pm 0.14 \mathrm{a}$ & $1.32 \pm 0.03 \mathrm{a}$ \\
& c-PTIO & $29.90 \pm 1.01 \mathrm{a}$ & $29.09 \pm 1.60 \mathrm{~b}$ & $28.77 \pm 1.36 \mathrm{~b}$ & $3.13 \pm 0.05 \mathrm{a}$ & $3.79 \pm 0.09 \mathrm{~b}$ & $1.38 \pm 0.15 \mathrm{a}$ \\
2 & Control & $31.33 \pm 1.14 \mathrm{a}$ & $8.75 \pm 0.24 \mathrm{~b}$ & $48.03 \pm 2.44 \mathrm{a}$ & $2.25 \pm 0.13 \mathrm{a}$ & $4.08 \pm 0.04 \mathrm{~b}$ & $1.55 \pm 0.05 \mathrm{a}$ \\
& NO & $30.61 \pm 1.48 \mathrm{a}$ & $18.33 \pm 0.49 \mathrm{a}$ & $38.85 \pm 1.51 \mathrm{~b}$ & $2.16 \pm 0.07 \mathrm{a}$ & $4.95 \pm 0.22 \mathrm{a}$ & $1.56 \pm 0.01 \mathrm{a}$ \\
& c-PTIO & $31.45 \pm 0.37 \mathrm{a}$ & $19.93 \pm 0.27 \mathrm{a}$ & $37.02 \pm 0.47 \mathrm{~b}$ & $1.56 \pm 0.02 \mathrm{~b}$ & $4.11 \pm 0.04 \mathrm{~b}$ & $1.70 \pm 0.04 \mathrm{a}$ \\
3 & Control & $30.23 \pm 0.32 \mathrm{a}$ & $10.34 \pm 0.04 \mathrm{a}$ & $46.49 \pm 2.28 \mathrm{~b}$ & $2.00 \pm 0.04 \mathrm{a}$ & $4.66 \pm 0.16 \mathrm{ab}$ & $2.09 \pm 0.03 \mathrm{a}$ \\
& NO & $30.90 \pm 0.17 \mathrm{a}$ & $11.39 \pm 0.33 \mathrm{a}$ & $46.79 \pm 1.21 \mathrm{~b}$ & $1.93 \pm 0.07 \mathrm{a}$ & $4.23 \pm 0.17 \mathrm{~b}$ & $2.09 \pm 0.03 \mathrm{a}$ \\
& c-PTIO & $31.19 \pm 0.04 \mathrm{a}$ & $7.12 \pm 0.11 \mathrm{~b}$ & $50.47 \pm 0.95 \mathrm{a}$ & $1.88 \pm 0.03 \mathrm{a}$ & $4.82 \pm 0.06 \mathrm{a}$ & $1.47 \pm 0.01 \mathrm{~b}$ \\
4 & Control & $59.02 \pm 0.49 \mathrm{ab}$ & $15.08 \pm 0.12 \mathrm{a}$ & $2.77 \pm 0.03 \mathrm{c}$ & $2.77 \pm 0.02 \mathrm{c}$ & $10.32 \pm 0.11 \mathrm{a}$ & $3.54 \pm 0.01 \mathrm{a}$ \\
& NO & $62.24 \pm 1.02 \mathrm{a}$ & $13.31 \pm 0.04 \mathrm{~b}$ & $3.86 \pm 0.02 \mathrm{a}$ & $3.86 \pm 0.04 \mathrm{a}$ & $8.84 \pm 0.12 \mathrm{~b}$ & $3.33 \pm 0.02 \mathrm{a}$ \\
& c-PTIO & $57.35 \pm 0.39 \mathrm{~b}$ & $15.72 \pm 0.12 \mathrm{a}$ & $3.08 \pm 0.05 \mathrm{~b}$ & $3.08 \pm 0.01 \mathrm{~b}$ & $9.88 \pm 0.14 \mathrm{ab}$ & $3.47 \pm 0.01 \mathrm{a}$ \\
\hline
\end{tabular}

Note: Within each acid type, different letters within the same week indicates significant differences at the level of 0.05 among different treatments.

Mitochondrial stearic acid (18:0) increased from 3.76\% at week $0 \%$ to $10.32 \%$ at week 4 . Treatment with NO decreased mitochondrial stearic acid levels during storage beyond week 2 . The mitochondrial stearic acid content of NO treated was 1.21 times the control in the 2 nd week, and only $85.7 \%$ of the control in the 4th week. The mitochondrial stearic acid content of c-PTIO-treated was only $82.9 \%$ of the control in the 1st week; Thereafter, there was no much discrepancy in the mitochondrial stearic acid content between the control and c-PTIO treated. 
Mitochondrial arachidic acid content increased from $0.81 \%$ at week $0 \%$ to $3.54 \%$ at week 4 . There were no apparent variations between the control and the NO treated during storage. Only in week 3 it found was that the mitochondrial arachidic acid content of c-PTIO treated was only $70.3 \%$ of the control.

\subsection{CBF Gene}

The expression level of $P p C B F 1$ in the control peach rose rapidly in the 1st week and then tended to stabilize (Fig. 7A). Exogenous NO treatment could significantly increase the expression level of PpCBF1. At the 4th week, the relative level of expression of $P p C B F 1$ in NO-treated peach fruits was about 1.51 times that of the control. There were no obvious variations in the level of expression of $P p C B F 1$ between the peach treated with c-PTIO and the control at week 4. Compared to $P p C B F 1$, the expression levels of $P p C B F 2, P p C B F 3$, and $P p C B F 4$ in peach were lower during cold storage (Figs. 7B-7D). In addition, both NO and c-PTIO had no significant effects on the expression levels of $P p C B F 2, P p C B F 3$, and $P p C B F 4$ when opposed to the control. The level of expression of $P p C B F 5$ in the control fruit increased to the maximum in the 1 st week and then decreased slightly (Fig. 7E). NO significantly increased the relative expression of $P p C B F 5$. During cold storage, the expression level of $P p C B F 5$ in NO-treated fruits was $1.65,1.97,3.13$, and 2.21 times that of the controls in the 1st, $2 \mathrm{nd}$, 3rd, and 3rd, respectively. c-PTIO partially reduced the expression of $P p C B F 5$. The relative expression level of $P p C B F 5$ from peaches treated with c-PTIO was $69.7 \%$ and $71.8 \%$ of the control in the 1 st and 4 th week, respectively. The level of expression of PpCBF6 in the control fruits increased continuously during cold storage (Fig. 7F). During cold storage, NO significantly increased the expression level of PpCBF6. The expression level of $P p C B F 6$ in NO-treated fruits was 1.77, 1.44, 1.40, and 1.61 times that of the control in the 1st, 2nd, 3rd and 4th week, respectively. The relative expression level of PpCBF6 of peaches treated with c-PTIO was only $63.8 \%$ and $52.0 \%$ of the control in the 3rd and 4th week, respectively. These results suggested that NO could promote the expression of $P p C B F 1 / 5 / 6$ to activate the cold resistance process in peaches. In addition, $P p C B F 2 / 3 / 4$ might contribute little to the response to cold stress, and exogenous NO had no significant influence on the expression of $P p C B F 2 / 3 / 4$.

\section{Discussion}

Nitric oxide is a signaling radical that interacts with and affects the function of a large number of biomolecules such as proteins and fatty acids [42]. Based on the fact that NO is a major regulator in plants in reaction to cold stress, and is specific in response to cold stress, we used the endogenous NO scavenger c-PTIO to verify the role of endogenous NO treatment on the physiological regulatory mechanisms of frozen peach fruit. In the present study, we demonstrated that $15 \mu \mathrm{mol} \mathrm{\textrm {L } ^ { - 1 }}$ of NO remarkable reduced the browning index and ion leakage rate during storage of peaches, increased GSNOR activity leading to the accumulation of SNOs, increased the NAD ${ }^{+} / \mathrm{NADH}$ and NADP ${ }^{+} / \mathrm{NADPH}$ ratios, maintained a high mitochondrial unsaturated fatty acid index and enhanced the expression of PpCBF $1 / 5 / 6$. NO treatment enhanced that activity of SOD. CAT, POD, and APX of the fruit mitochondria, reduced the accumulation of hydrogen peroxide, inhibited the accumulation of ROS, and thus improved the defense capacity of the antioxidant system to mitigate oxidative damage in peach fruit. c-PTIO showed the opposite effect as a NO scavenger, confirming the beneficial regulatory effect of NO during postharvest storage.

Under the right ecological conditions, the level of ROS in cells is located in dynamic balancing. Stress will create the accumulation of large-scale ROS in plants, membrane lipid peroxide reaction, and ultimately disruption of plant metabolism [43]. SOD, CAT, POD, and APX are the four key enzymes in the enzymatic defense of plants, and CAT, POD, and APX are the most crucial involved in inhibiting the increase of $\mathrm{H}_{2} \mathrm{O}_{2}$. In our current research, NO significantly enhanced SOD, POD, CAT, and APX activities in peach fruit mitochondria (Fig. 3), reduced MDA content, and decreased $\mathrm{H}_{2} \mathrm{O}_{2}$ content in fruit. These results suggest 
that NO increases ROS scavenging capacity through the activity of antioxidant enzymes, and that $\mathrm{H}_{2} \mathrm{O}_{2}$ induces de novo synthesis and acts as the main substrate for POD, stimulating the rising of POD activity and keeping ROS levels low in peach fruit mitochondria. Thus it protects the integrity of cell membranes and delays the oxidative damage and senescence in peach fruit mitochondria. GSNOR is a pivotal regulator of $S$-nitrosylation in plant response to various stresses, catalyzes the conversion of GSNO to oxidized glutathione (GSSG) and ammonia, and is under an obligation to liberate levels of ROS and RNS [44]. SNOs are the products of $S$-nitrosylation modification by NO and response to abiotic stress of plants [45]. The increased SNOs are considered a collective response against stress, and SNOs might be more susceptible to low-temperature stress [46]. Exogenous NO treatment uncommonly promoted the activity of GSNOR and the content of SNOs in mitochondria, while c-PTIO reduced mitochondrial GSNOR activity and SNOs content, suggesting that exogenous NO could promote the tolerance of peaches to cold stress and maintain a balanced level of ROS. As an ubiquitous second messenger, $\mathrm{Ca}^{2+}$ plays a decisive role against oxidative stress [47]. Mitochondrial $\mathrm{Ca}^{2+}$ also regulates mitochondrial metabolism and energy production of mitochondria [48]. $S$-nitrosylation suggests crosstalk between NO and calcium signaling upon low-temperature [46]. Exogenous NO increased mitochondrial $\mathrm{Ca}^{2+}$ content, which might also help to alleviate oxidative stress induced by ROS in mitochondria, maintain energy and the membrane integrity of mitochondria under freezing stress. NAD and NADP involve in the process of energy production, the antioxidation capacity, and mitochondrial activity, and mediates $\mathrm{Ca}^{2+}$ homeostasis $[49,50]$. The redox states, NADH and NADPH, are significant factors in antioxidation and ROS generation [50]. The high ratio of $\mathrm{NAD}^{+} / \mathrm{NADH}$ and $\mathrm{NADP}^{+} / \mathrm{NADPH}$ in mitochondria of peaches treated with $\mathrm{NO}$ was in accordance with the results that NO reduced the peroxidation of mitochondrial fatty acids, maintained the balance of mitochondrial redox, and improved mitochondrial $\mathrm{Ca}^{2+}$ homeostasis.
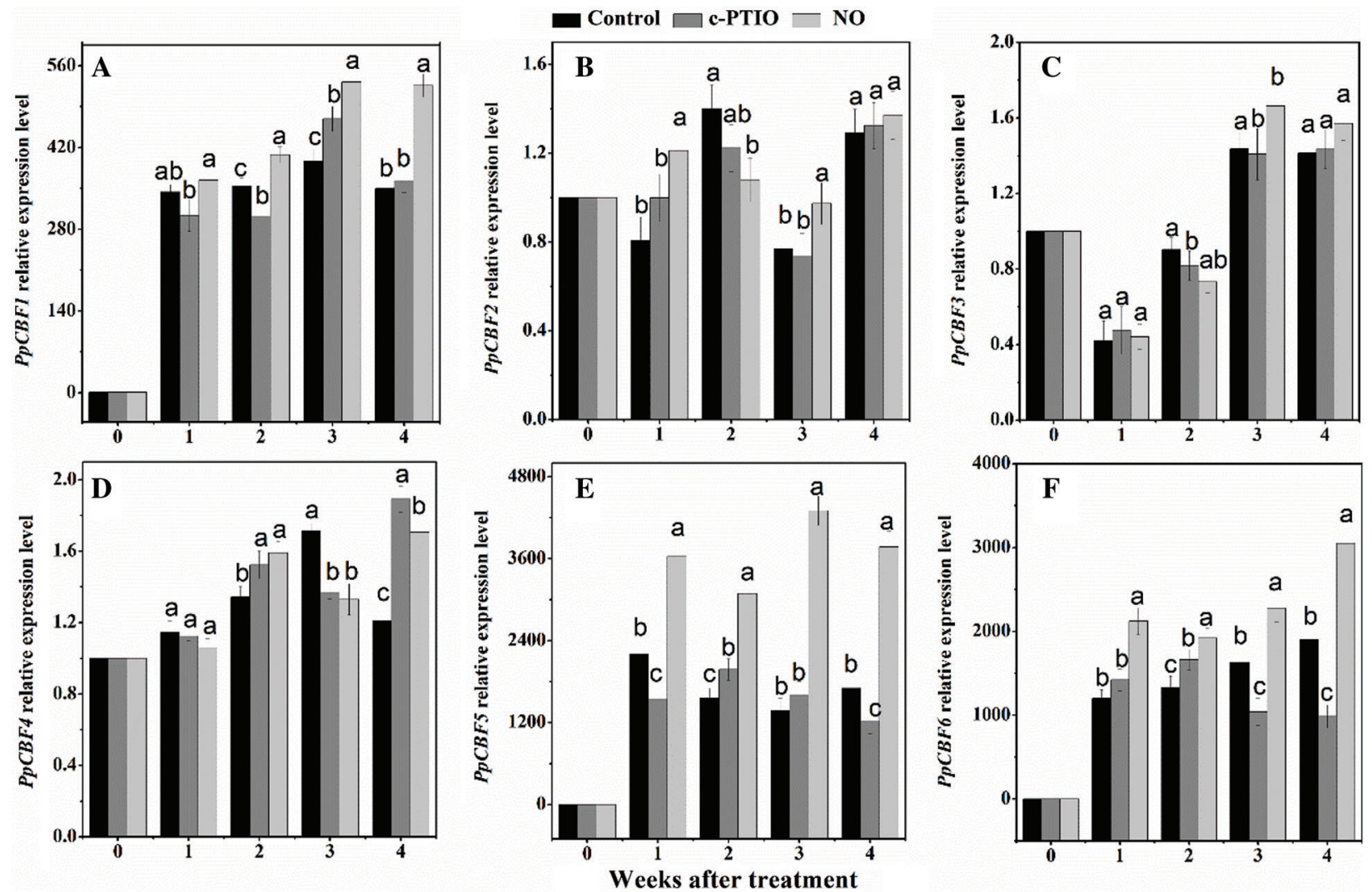

Figure 7: Changes in the relative expression levels of $C B F$ genes (A-F) in peaches during cold storage. Vertical bars represent standard deviations of the means of triplication 
Mitochondrial fatty acid composition is essential for the function and structure of mitochondria [51]. The metabolism and composition of mitochondrial lipids changes with aging, and mitochondrial lipid peroxidation is an emerging target in the aging process [52]. The concentration of MDA, the end product of lipid peroxidation, is a marker of lipid peroxidation $[53,54]$. LOX is a lipid-peroxidizing enzyme destroying unsaturated fatty acids, such as linoleic acid, linolenic acid, and arachidonic acid, to be hydroperoxy octadecadienoic acid, hydroperoxy octadecatrienoic acid, and hydroperoxy eicosatetraenoic acid, respectively [55,56]. Compare to other treatments, NO-treated peaches had lower mitochondrial MDA content and lower mitochondrial LOX activity, indicating that NO can reduce mitochondrial lipid peroxidation. Linoleic acid, $\alpha$-linolenic acid, and oleic acid were the unsaturated fatty acids detected in the mitochondrial fatty acids. Unsaturated fatty acids increase membrane fluidity, thereby maintaining membrane lipid stability and improving the cold resistance of plants [57]. During the first 3 weeks of this study, the proportion of unsaturated fatty acids was consistently higher than that of saturated fatty acids in the different treatments. The unsaturated fatty acid content decreased to $23.56 \%$ at week 4 , indicating a decrease in freezing resistance in Feicheng peach, which is consistent with an increase in mitochondrial MDA content. NO treatment did not alter the mitochondrial fatty acid composition of peach fruit during chilling, but maintained a higher mitochondrial IUFA. Linoleic acid, $\alpha$-linolenic acid, and oleic acid are the major unsaturated fatty acids in many membrane lipids and plays an important intrinsic role as an antioxidant. Elevated standards of unsaturated fatty acids in mitochondria may enhance the antioxidant capacity of peach mitochondria. The degree of unsaturation of fatty acids in mitochondrial membrane fats is also closely related to the degree of freezing damage in fruit when unsaturated fatty acids in mitochondria are broken down or converted to saturated fatty acids. When unsaturated fatty acids in mitochondria were broken down or converted to saturated fatty acids, the fluidity of mitochondrial membranes decreased, and the phase transition temperature of membranes increased. This made them highly susceptible to low-temperature conditions and ultimately exacerbated the extent of cold damage caused by low temperatures. Compared with other treatments, NO maintained a higher mitochondrial unsaturated fatty acid content and increased the proportion of unsaturated fatty acids, thus improving antioxidant capacity, reducing mitochondrial fatty acid peroxidation, and maintaining the stability of mitochondrial membranes during cold storage. Palmitic acid is the basic fatty acid of various membrane lipids and plays an important role in the antioxidant effect of plants. The experimental results showed that apart from the unsaturated fatty acids linoleic and linolenic, the content of palmitic acid was the highest, and the higher palmitic acid content could improve the antioxidant effect of peach fruit mitochondria.

The CBF-dependent pathway plays a nucleus activity in the regulation of the frosty stress response in plants [12]. In this study, six CBF genes ( $P p C B F$ 1-6) were of a varied deliverance in peach fruit during frozen storage. $C B F 1 / 5 / 6$ was significantly induced by low temperature and gene expression subjoin apace, and all at a high level. Relative to the control, NO treatment significantly increased $C B F 1 / 5 / 6$ gene expression during cold storage, while c-PTIO resulted in slightly lower gene expression of $C B F 1 / 5 / 6$ than the control by scavenging NO. The low expression of $C B F 2 / 3 / 4$ in peach fruit indicated that these three genes were not induced by low temperature [58] and did not differ significantly between treatments. This suggests that NO may not be participating in the regulation and control of the expression of these three genes and that the role of $C B F 2 / 3 / 4$ in the cold resistance pathway needs to be further explored. It has been shown that peach pairs of CBF family genes have different roles in low-temperature storage, with $C B F 1 / 5 / 6$ being significantly induced by low temperature due to having an intact ICErl-like lowtemperature response module. In turn $C B F 2 / 3 / 4$ does not have this module and is not induced by lowtemperature expression. This study also suggests that $C B F 1 / 5 / 6$ have different freezing response patterns, with $C B F 1$ and $C B F 5$ being associated with cold resistance in early peach fruit, while $C B F 6$ may be involved in long-term cold resistance in peach fruit [58]. Despite differences in the $C B F$ family between 
tomato fruit and peach, similar upregulation of $C B F$ expression by NO has been posted in harvested tomato fruit treated with a NO donor (sodium nitrate).

Low temperatures lead to a rise in ROS levels and oxidative stress in the mitochondria, causing oxidative damage on it. Exogenous NO subjoins the activity of antioxidants and other enzymes in the mitochondria to promote ROS clearance on this plant organelle. As shown in Fig. 8, exogenous NO increased the antioxidant capacity of the mitochondria, reduced the levels of oxidation products such as $\mathrm{H}_{2} \mathrm{O}_{2}$ and MDA in peach fruits, delayed the process of cold damage, and preserved the quality of peach fruits during the cold storage process. NO treatment promotes the stability of the unsaturated fatty acid content in the mitochondria and inhibits the conversion of unsaturated fatty acids by reducing the activity of LOX. This preservs the unsaturation of fatty acids in the mitochondria, which helps to improve the cold tolerance of peach fruits, reduces the MDA content in the mitochondria, reduces the peroxidation of mitochondrial fatty acids and the oxidative damage caused by ROS and the composition of the mitochondrial fatty acids and the mitochondrial integrity, activation of downstream cold resistance genes, alleviation of cold damage in peach fruits, and improvement of the peach tolerance to cold stress during storage. However, increasing evidence confirms that nitro fatty acids, products made from unsaturated fatty acids and NO, play an important role in the defense mechanisms of plants under abiotic and oxidative stress [59-61]. In this work, we reported the main effects of NO on mitochondrial fatty acids. As an important organelle, mitochondria play a pivotal role in fruits in response to cold stress. Further studies are needed to investigate the role of nitro fatty acids in regulating mitochondrial function and cold resistance of the fruit during storage.

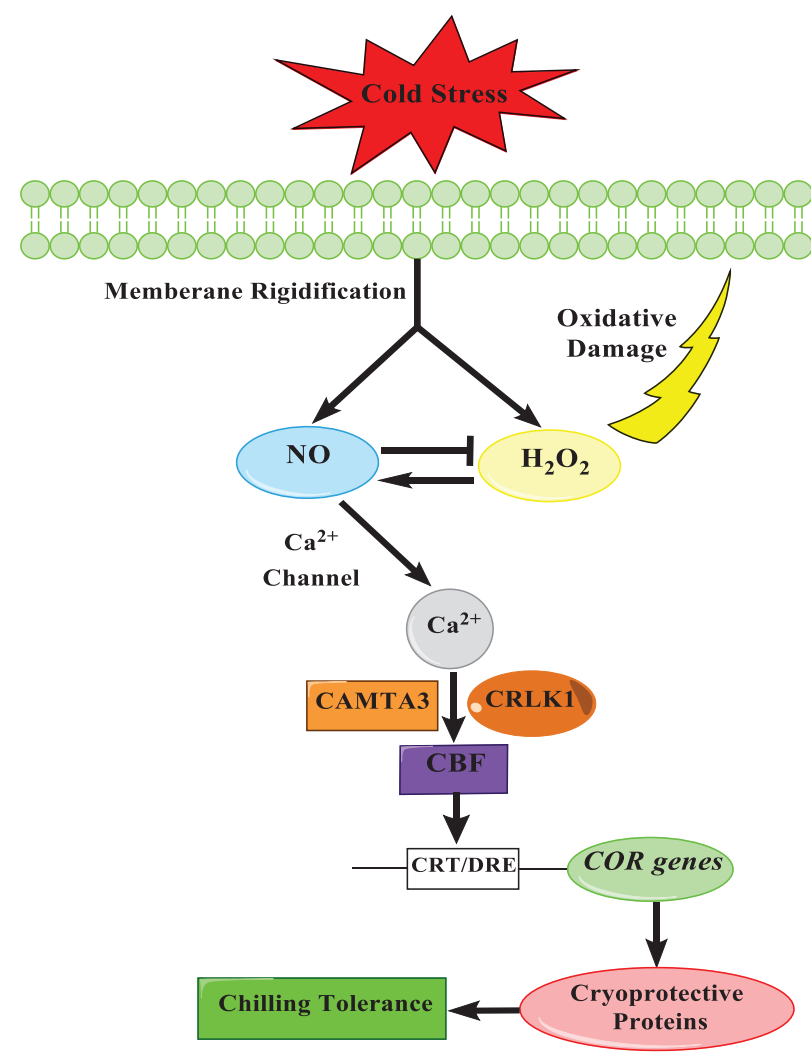

Figure 8: The possible pathway that NO regulates $C B F$ in peaches during cold storage 
Authorship and Contribution: Xiaoshan Guo: Investigation, Writing-original draft, Formal analysis. Dandan Huang: Methodology, Project administration, Validation, Visualization, Writing-review \& editing. Siyu Wen and Yang Bai: Software, Data curation. Shuhua Zhu and Jianrong Feng: Funding acquisition, Conceptualization, Supervision, Resources, Writing-review \& editing.

Funding Statement: This work was supported by the National Natural Science Foundation of China (31800581 and 32071808).

Conflicts of Interest: The authors declare that they have no conflicts of interest to report regarding the present study.

\section{References}

1. Rodrigues, C., Gaspar, P. D., Simões, M. P., Silva, P. D., Andrade, L. P. (2020). Review on techniques and treatments toward the mitigation of the chilling injury of peaches. Journal of Food Processing and Preservation, e14358. DOI 10.1111/jfpp.14358.

2. Brizzolara, S., Hertog, M., Tosetti, R., Nicolai, B., Tonutti, P. (2018). Metabolic responses to low temperature of three peach fruit cultivars differently sensitive to cold storage. Frontiers in Plant Science, 9, 706. DOI 10.3389/ fpls.2018.00706.

3. Brizzolara, S., Manganaris, G. A., Fotopoulos, V., Watkins, C. B., Tonutti, P. (2020). Primary metabolism in fresh fruits during storage. Frontiers in Plant Science, 11, 80. DOI 10.3389/fpls.2020.00080.

4. Huang, D., Tian, W., Feng, J., Zhu, S. (2020). Interaction between nitric oxide and storage temperature on sphingolipid metabolism of postharvest peach fruit. Plant Physiology and Biochemistry, 151, 60-68. DOI 10.1016/j.plaphy.2020.03.012.

5. Liang, S. M., Kuang, J. F., Ji, S. J., Chen, Q. F., Deng, W. et al. (2020). The membrane lipid metabolism in horticultural products suffering chilling injury, Food Quality and Safety, 4, 9-14. DOI 10.1093/fqsafe/fyaa001.

6. Cassim, A. M., Gouguet, P., Gronnier, J., Laurent, N., Germain, V. et al. (2019). Plant lipids: Key players of plasma membrane organization and function. Progress in Lipid Research, 73, 1-27. DOI 10.1016/j.plipres.2018.11.002.

7. Kong, X., Wei, B., Gao, Z., Zhou, Y., Shi, F. et al. (2017). Changes in membrane lipid composition and function accompanying chilling injury in bell peppers. Plant and Cell Physiology, 59, 167-178. DOI 10.1093/pcp/pcx171.

8. Wang, L., Bokhary, S. U. F., Xie, B., Hu, S., Jin, P. et al. (2019). Biochemical and molecular effects of glycine betaine treatment on membrane fatty acid metabolism in cold stored peaches. Postharvest Biology and Technology, 154, 58-69. DOI 10.1016/j.postharvbio.2019.04.007.

9. Huang, Q., Qian, X., Jiang, T., Zheng, X. (2019). Effect of eugenol fumigation treatment on chilling injury and CBF gene expression in eggplant fruit during cold storage. Food Chemistry, 292, 143-150. DOI 10.1016/j. foodchem.2019.04.048.

10. Liang, L., Zhang, B., Yin, X. R., Xu, C. J., Sun, C. D. et al. (2013). Differential expression of the $C B F$ gene family during postharvest cold storage and subsequent shelf-life of peach fruit. Plant Molecular Biology Reporter, 31, 1358-1367. DOI 10.1007/s11105-013-0600-5.

11. Song, Q., Wang, X., Li, J., Chen, T. H. H., Liu, Y. et al. (2021). CBF1 and CBF4 in solanum tuberosum L. differ in their effect on low-temperature tolerance and development. Environmental and Experimental Botany, 185, 104416. DOI 10.1016/j.envexpbot.2021.104416.

12. Shi, Y., Ding, Y., Yang, S. (2018). Molecular regulation of CBF signaling in cold acclimation. Trends in Plant Science, 23, 623-637. DOI 10.1016/j.tplants.2018.04.002.

13. Fang, P., Wang, Y., Wang, M., Wang, F., Chi, C. et al. (2021). Crosstalk between brassinosteroid and redox signaling contributes to the activation of $\mathrm{CBF}$ expression during cold responses in tomato. Antioxidants, 10, 509. DOI 10.3390/antiox10040509.

14. Singh, V. P., Tripathi, D. K., Fotopoulos, V. (2020). Hydrogen sulfide and nitric oxide signal integration and plant development under stressed/non-stressed conditions. Physiologia Plantarum, 168, 239-240. DOI 10.1111/ ppl.13066. 
15. Sun, C., Zhang, Y., Liu, L., Liu, X., Li, B. et al. (2021). Molecular functions of nitric oxide and its potential applications in horticultural crops. Horticulture Research, 8, 71. DOI 10.1038/s41438-021-00500-7.

16. Gupta, P., Seth, C. S. (2020). Interactive role of exogenous 24 epibrassinolide and endogenous NO in Brassica juncea L. under salinity stress: Evidence for NR-dependent NO biosynthesis. Nitric Oxide, 97, 33-47. DOI 10.1016/j.niox.2020.01.014.

17. Ma, Y., Huang, D., Chen, C., Zhu, S., Gao, J. (2019). Regulation of ascorbate-glutathione cycle in peaches via nitric oxide treatment during cold storage. Scientia Horticulturae, 247, 400-406. DOI 10.1016/j. scienta.2018.12.039.

18. Zhang, T., Che, F., Zhang, H., Pan, Y., Xu, M. et al. (2017). Effect of nitric oxide treatment on chilling injury, antioxidant enzymes and expression of the $\mathrm{CmCBF} 1$ and $\mathrm{CmCBF} 3$ genes in cold-stored hami melon (Cucumis melo L.) fruit. Postharvest Biology and Technology, 127, 88-98. DOI 10.1016/j.postharvbio.2017.01.005.

19. Zhu, S., Zhou, J. (2006). Effects of nitric oxide on fatty acid composition in peach fruits during storage. Journal of Agricultural and Food Chemistry, 54, 9447-9452. DOI 10.1021/jf062451u.

20. Begara-Morales, J. C., Mata-Pérez, C., Padilla, M. N., Chaki, M., Valderrama, R. et al. (2020). Role of electrophilic nitrated fatty acids during development and response to abiotic stress processes in plants. Journal of Experimental Botany, 72, 917-927. DOI 10.1093/jxb/eraa517.

21. Gupta, K. J., Kumari, A., Florez-Sarasa, I., Fernie, A. R., Igamberdiev, A. U. (2018). Interaction of nitric oxide with the components of the plant mitochondrial electron transport chain. Journal of Experimental Botany, 69, 3413-3424. DOI 10.1093/jxb/ery119.

22. Huang, D., Hu, S., Zhu, S., Feng, J. (2019). Regulation by nitric oxide on mitochondrial permeability transition of peaches during storage. Plant Physiology and Biochemistry, 138, 17-25. DOI 10.1016/j.plaphy.2019.02.020.

23. Kastaniotis, A. J., Autio, K. J., Kerätär, J. M., Monteuuis, G., Mäkelä, A. M. et al. (2017). Mitochondrial fatty acid synthesis, fatty acids and mitochondrial physiology. Biochimica et Biophysica Acta (BBA)-Molecular and Cell Biology of Lipids, 1862, 39-48. DOI 10.1016/j.bbalip.2016.08.011.

24. Ding, Y., Shi, Y., Yang, S. (2019). Advances and challenges in uncovering cold tolerance regulatory mechanisms in plants. New Phytologist, 222, 1690-1704. DOI 10.1111/nph.15696.

25. Jing, G., Zhou, J., Zhu, S. (2016). Effects of nitric oxide on mitochondrial oxidative defence in postharvest peach fruits. Journal of the Science of Food and Agriculture, 96, 1997-2003. DOI 10.1002/jsfa.7310.

26. Lim, M. D., Lorković, I. M., Ford, P. C. (2005). The preparation of anaerobic nitric oxide solutions for the study of heme model systems in aqueous and nonaqueous media: Some consequences of NOx impurities. Methods in Enzymology, 396, 3-17. DOI 10.1016/S0076-6879(05)96001-1.

27. Wang, Q., Wei, Y. Y., Chen, X. Y., Xu, W. J., Wang, N. et al. (2020). Postharvest strategy combining maturity and storage temperature for 1-mCP-treated peach fruit. Journal of Food Processing and Preservation, 44, e14388. DOI 10.1111/jfpp. 14388 .

28. Patterson, B. D., MacRae, E. A., Ferguson, I. B. (1984). Estimation of hydrogen peroxide in plant extracts using titanium(IV). Analytical Biochemistry, 139, 487-492. DOI 10.1016/0003-2697(84)90039-3.

29. Liu, J. L., Sun, J. H., Pan, Y. G., Yun, Z., Zhang, Z. K. et al. (2021). Endogenous melatonin generation plays a positive role in chilling tolerance in relation to redox homeostasis in litchi fruit during refrigeration. Postharvest Biology and Technology, 178, 111554. DOI 10.1016/j.postharvbio.2021.111554.

30. Wang, Y. X., Gao, L. P., Wang, Q., Zuo, J. H. (2019). Low temperature conditioning combined with methyl jasmonate can reduce chilling injury in bell pepper. Scientia Horticulturae, 243, 434-439. DOI 10.1016/j. scienta.2018.08.031.

31. Baniebrahim, S., Pishkar, L., Iranbakhsh, A., Talei, D., Barzin, G. (2021). Physiological and molecular responses of black cumin (Nigella sativa L.) seedlings to silver nanoparticles. Journal of Plant Nutrition. DOI 10.1080/ 01904167.2021.1927086.

32. Ghosh, A., Saha, I., Debnath, S. C., Hasanuzzaman, M., Adak, M. K. (2021). Chitosan and putrescine modulate reactive oxygen species metabolism and physiological responses during chili fruit ripening. Plant Physiology and Biochemistry, 163, 55-67. DOI 10.1016/j.plaphy.2021.03.026. 
33. Xu, Y., Li, X., Huang, J., Peng, L., Luo, D. et al. (2020). A simplified method to isolate rice mitochondria. Plant Methods, 16, 149. DOI 10.1186/s13007-020-00690-6.

34. Bradford, M. M. (1976). A rapid and sensitive method for the quantitation of microgram quantities of protein utilizing the principle of protein-dye binding. Analytical Biochemistry, 72, 248-254. DOI 10.1016/0003-2697 (76)90527-3.

35. Sakamoto, A., Ueda, M., Morikawa, H. (2002). Arabidopsis glutathione-dependent formaldehyde dehydrogenase is an S-nitrosoglutathione reductase. FEBS Letters, 515, 20-24. DOI 10.1016/s0014-5793(02)02414-6.

36. Frungillo, L., de Oliveira, J. F., Saviani, E. E., Oliveira, H. C., Martinez, M. C. et al. (2013). Modulation of mitochondrial activity by $S$-nitrosoglutathione reductase in Arabidopsis thaliana transgenic cell lines. Biochimica et Biophysica Acta (BBA)-Bioenergetics, 1827, 239-247. DOI 10.1016/j.bbabio.2012.11.011.

37. Shi, F., Zhou, X., Zhou, Q., Tan, Z., Yao, M. M. et al. (2018). Membrane lipid metabolism changes and aroma ester loss in low-temperature stored nanguo pears. Food Chemistry, 245, 446-453. DOI 10.1016/j. foodchem.2017.10.091.

38. Senthilkumar, M., Amaresan, N., Sankaranarayanan, A. (2021). Estimation of malondialdehyde (MDA) by thiobarbituric acid (TBA) assay. Plant-microbe interactions, pp. 103-105. Springer Protocols Handbooks. Humana, New York, NY, DOI 10.1007/978-1-0716-1080-0_25.

39. Palma, F., Lopez-Gomez, M., Tejera, N. A., Lluch, C. (2013). Salicylic acid improves the salinity tolerance of medicago sativa in symbiosis with sinorhizobium meliloti by preventing nitrogen fixation inhibition. Plant Science, 208, 75-82. DOI 10.1016/j.plantsci.2013.03.015.

40. Meisel, L., Fonseca, B., Gonzalez, S., Baeza-Yates, R., Cambiazo, V. et al. (2005). A rapid and efficient method for purifying high quality total RNA from peaches (Prunus persica) for functional genomics analyses. Biological Research, 38, 83-88. DOI 10.4067/s0716-97602005000100010.

41. Guan, Y., Liu, S., Wu, W., Hong, K., Li, R. et al. (2021). Genome-wide identification and cold stress-induced expression analysis of the CBF gene family in Liriodendron chinense. Journal of Forestry Research. DOI 10.1007/s11676-020-01275-8.

42. Corpas, F. J., Gonzalez-Gordo, S., Palma, J. M. (2020). Nitric oxide: A radical molecule with potential biotechnological applications in fruit ripening. Journal of Biotechnology, 324, 211-219. DOI 10.1016/j. jbiotec.2020.10.020.

43. Su, Y., Huang, Y., Dong, X., Wang, R., Tang, M. et al. (2021). Exogenous methyl jasmonate improves heat tolerance of perennial ryegrass through alteration of osmotic adjustment, antioxidant defense, and expression of jasmonic acid-responsive genes. Frontiers in Plant Science, 12, 664519. DOI 10.3389/fpls.2021.664519.

44. Petřivalský, M., Kubienová, L., Tichá, T., Luhová, L. (2015). S-Nitrosoglutathione reductase: A key regulator of S-nitrosylation in plant development and stress responses. In: Gupta, K., Igamberdiev, A. (eds), Reactive oxygen and nitrogen species signaling and communication in plants. Signaling and Communication in Plants, vol. 23. Springer, Cham. DOI 10.1007/978-3-319-10079-1_14.

45. Begara-Morales, J. C., Chaki, M., Valderrama, R., Mata-Pérez, C., Padilla, M. N. et al. (2019). The function of $S$ nitrosothiols during abiotic stress in plants. Journal of Experimental Botany, 70, 4429-4439. DOI 10.1093/jxb/ erz197.

46. Zhang, J., Liao, W. (2020). Protein S-nitrosylation in plant abiotic stresses. Functional Plant Biology, 47, 1-10. DOI 10.1071/FP19071.

47. Malik, Z., Afzal, S., Danish, M., Abbasi, G. H., Bukhari, S. A. H. et al. (2020). Role of nitric oxide and calcium signaling in abiotic stress tolerance in plants, pp. 563-581. DOI 10.1002/9781119552154.ch28.

48. Giorgi, C., Marchi, S., Pinton, P. (2018). The machineries, regulation and cellular functions of mitochondrial calcium. Nature Reviews Molecular Cell Biology, 19, 713-730. DOI 10.1038/s41580-018-0052-8.

49. Blacker, T. S., Duchen, M. R. (2016). Investigating mitochondrial redox state using NADH and NADPH autofluorescence. Free Radical Biology and Medicine, 100, 53-65. DOI 10.1016/j.freeradbiomed.2016.08.010.

50. Ying, W. (2008). NAD ${ }^{+} / \mathrm{NADH}$ and $\mathrm{NADP}^{+} / \mathrm{NADPH}$ in cellular functions and cell death: Regulation and biological consequences. Antioxidants \& Redox Signaling, 10, 179-206. DOI 10.1089/ars.2007.1672. 
51. Tamura, Y., Kawano, S., Endo, T. (2020). Lipid homeostasis in mitochondria. Biological Chemistry, 401, 821-833. DOI 10.1515/hsz-2020-0121.

52. Ademowo, O. S., Dias, H., Burton, D. G., Griffiths, H. R. (2017). Lipid (per) oxidation in mitochondria: An emerging target in the ageing process? Biogerontology, 18, 859-879. DOI 10.1007/s10522-017-9710-z.

53. Jové, M., Mota-Martorell, N., Pradas, I., Martín-Gari, M., Ayala, V. et al. (2020). The advanced lipoxidation endproduct malondialdehyde-lysine in aging and longevity. Antioxidants, 9, 1132. DOI 10.3390/antiox9111132.

54. Khoubnasabjafari, M., Jouyban, A. (2020). Challenges on determination of malondialdehyde in plant samples. Archives of Crop Science, 4, 64-66. DOI 10.36959/718/604.

55. Braidot, E., Petrussa, E., Micolini, S., Tubaro, F., Vianello, A. et al. (2004). Biochemical and immunochemical evidences for the presence of lipoxygenase in plant mitochondria. Journal of Experimental Botany, 55, 16551662. DOI 10.1093/jxb/erh197.

56. Viswanath, K. K., Varakumar, P., Pamuru, R. R., Basha, S. J., Mehta, S. et al. (2020). Plant lipoxygenases and their role in plant physiology. Journal of Plant Biology, 63, 83-95. DOI 10.1007/s12374-020-09241-x.

57. He, M., Qin, C. X., Wang, X., Ding, N. Z. (2020). Plant unsaturated fatty acids: Biosynthesis and regulation. Frontiers in Plant Science, 11, 390. DOI 10.3389/fpls.2020.00390.

58. Liang, L., Zhang, B., Yin, X. R., Xu, C. J., Sun, C. D. et al. (2013). Differential expression of the CBF gene family during postharvest cold storage and subsequent shelf-life of peach fruit. Plant Molecular Biology Reporter, 31, 1358-1367. DOI 10.1007/s11105-013-0600-5.

59. Kolbert, Z., Lindermayr, C., Loake, G. J. (2021). The role of nitric oxide in plant biology: Current insights and future perspectives. Journal of Experimental Botany, 72, 777-780. DOI 10.1093/jxb/erab013.

60. Mata-Pérez, C., Padilla, M. N., Sánchez-Calvo, B., Begara-Morales, J. C., Valderrama, R. et al. (2018). Biological properties of nitro-fatty acids in plants. Nitric Oxide, 78, 176-179. DOI 10.1016/j.niox.2018.03.011.

61. Mata-Pérez, C., Sánchez-Calvo, B., Padilla, M. N., Begara-Morales, J. C., Valderrama, R. et al. (2017). Nitro-fatty acids in plant signaling: New key mediators of nitric oxide metabolism. Redox Biology, 11, 554-561. DOI 10.1016/ j.redox.2017.01.002. 